\title{
Monitoring daily physical activity of upper extremity in young and adolescent boys with Duchenne muscular dystrophy
}

Citation for published version (APA):

van der Geest, A., Essers, J. M. N., Bergsma, A., Jansen, M., \& de Groot, I. J. M. (2020). Monitoring daily physical activity of upper extremity in young and adolescent boys with Duchenne muscular dystrophy: A pilot study. Muscle \& Nerve, 61(3), 293-300. https://doi.org/10.1002/mus.26763

Document status and date:

Published: 01/03/2020

DOI:

10.1002/mus.26763

Document Version:

Publisher's PDF, also known as Version of record

\section{Document license:}

Taverne

Please check the document version of this publication:

- A submitted manuscript is the version of the article upon submission and before peer-review. There can be important differences between the submitted version and the official published version of record.

People interested in the research are advised to contact the author for the final version of the publication, or visit the DOI to the publisher's website.

- The final author version and the galley proof are versions of the publication after peer review.

- The final published version features the final layout of the paper including the volume, issue and page numbers.

Link to publication

\footnotetext{
General rights rights.

- You may freely distribute the URL identifying the publication in the public portal. please follow below link for the End User Agreement:

www.umlib.nl/taverne-license

Take down policy

If you believe that this document breaches copyright please contact us at:

repository@maastrichtuniversity.nl

providing details and we will investigate your claim.
}

Copyright and moral rights for the publications made accessible in the public portal are retained by the authors and/or other copyright owners and it is a condition of accessing publications that users recognise and abide by the legal requirements associated with these

- Users may download and print one copy of any publication from the public portal for the purpose of private study or research.

- You may not further distribute the material or use it for any profit-making activity or commercial gain

If the publication is distributed under the terms of Article $25 \mathrm{fa}$ of the Dutch Copyright Act, indicated by the "Taverne" license above, 


\title{
Monitoring daily physical activity of upper extremity in young and adolescent boys with Duchenne muscular dystrophy: A pilot study
}

\author{
Annette van der Geest MD ${ }^{1} \quad$ Johannes M. N. Essers MSc ${ }^{2} \quad$ Arjen Bergsma PhD ${ }^{3}$ | \\ Merel Jansen PT, $\mathrm{PhD}^{1}$ ( ) | Imelda J. M. de Groot MD, $\mathrm{PhD}^{1}$
}

${ }^{1}$ Department of Rehabilitation, Donders Institute for Brain, Cognition and Behaviour, Radboud University Medical Centre, Nijmegen, The Netherlands

${ }^{2}$ Department of Nutrition and Movement Sciences, Maastricht University Medical Centre, Maastricht, The Netherlands

${ }^{3}$ Technical Medical Centre Department of Biomechanical Engineering, University of Twente, Enschede, The Netherlands

\section{Correspondence}

Annette van der Geest, Department of Rehabilitation, Donders Institute for Brain, Cognition and Behaviour, Radboud University Medical Centre, Nijmegen, The Netherlands.

Email: annettevdgeest@gmail.com

\section{Present address}

Annette van der Geest is currently working at Department of Rehabilitation Physical Therapy Science \& Sport, UMC Utrecht Brain Centre, Utrecht, The Netherlands.

Funding information

Duchenne Parent Project (to I.J.M.d.G.)

\begin{abstract}
Introduction: Accelerometry of the upper extremity (UE) potentially provides information on the extent of activities in daily life in patients with Duchenne muscular dystrophy (DMD). The objective of this study is to evaluate the validity of home measurements of UE accelerometry.

Methods: This was a cross-sectional study in 16 patients with DMD (aged 7-17 years). Patients were monitored for 1 to 3 days with two accelerometers on the UE and one accelerometer on the wheelchair.

Results: The mean intensity of activity and the mean frequency of transfers of arm elevation from low to middle were approximately twofold higher in patients with a Brooke scale score of 1 or 2 than in patients with a Brooke scale score of 3 or 4 . Correlations with the Performance of Upper Limb scale score were high for intensity and for the total frequency of arm elevations per hour.

Discussion: Intensity, percentage of time in middle orientation, and frequency of transfers of the upper arm correlated well with functional measurements.
\end{abstract}

\section{KEYWORDS}

accelerometer, ambulant, DMD, Duchenne muscular dystrophy, monitoring, physical activity, upper extremity

\section{1 | INTRODUCTION}

In children/adolescents with Duchenne muscular dystrophy (DMD), progressive weakness results in loss of ambulation at a mean age of 13 years when treated with corticosteroids. ${ }^{1}$ From about 11 years onward, the Brooke scale score (grading the upper extremity [UE] activity level in boys/adolescents with DMD) starts to increase,

Abbreviations: DMD, Duchenne muscular dystrophy; LA, lower arm; PUL, Performance of Upper Limb; UA, upper arm; UE, upper extremity. indicating a decline in UE function. Because of this, in combination with increased life expectancy, males with DMD now live longer with functional limitations of the UE and $70 \%$ experience UE limitations when performing social activities. ${ }^{2-4}$

To evaluate the effect of treatments on daily activity, an objective measure with standardized information is required. ${ }^{5-8}$ Although functional outcomes provide information about the level of functional capacity and activity function, ${ }^{9}$ it is unclear how these can be generalized to actual daily life performance. Evaluating UE function in home settings will give better insights. Currently, diaries are widely used; 
however, they are time consuming for patients, subjective, and, therefore, probably less reliable. ${ }^{10,11}$ Accelerometers could provide a more objective measure. ${ }^{12}$

Accelerometers have been shown to be useful in monitoring gait (eg, overall physical activity level, step activity and gait alterations) in boys with DMD and in children with other neurological diseases. ${ }^{13-21}$ Most of the experience with the use of accelerometers in the UEs is in adult patients with stroke and multiple sclerosis. ${ }^{22-25}$ Uswatte et $\mathrm{al}^{26}$ showed that if complementary self-reported measures are used simultaneously they can provide rich information about UE activities. In children with DMD, a movement monitor for UE movements was tested during specific tasks in a controlled setting ${ }^{27}$ but not in a home situation.

In previous studies with accelerometers to measure UE function, various parameters were used. Intensity (or movement counts) of movement was recommended as a parameter in several studies. $^{23,24,28,29}$ Koene et al ${ }^{12}$ questioned the relationship between measured intensity and UE function in children with mitochondrial disease because a high level of nonpurposeful activity influences the registration of the parameter intensity. However, this specifically applies to children with movement disorders such as ataxia. Other mentioned parameters are the duration of arm use in combination with a jerk index, level of arm elevation, mean of rotation rate, and elevation rate. $^{12,25,27}$ The objective of this pilot study was to evaluate the validity of three acceleration-based parameters on UE activity in at-home situations as an outcome measure in ambulant and wheelchair dependent boys/adolescents with DMD.

\section{2 | MATERIALS AND METHODS}

\section{$2.1 \quad$ Study design and participants}

Eligible participants were boys/adolescent boys ranging in age from 7 to 17 years with a DNA-established diagnosis of DMD who were ambulant or wheelchair dependent with a Brooke scale score of 1-4 (this will be discussed more fully below in Clinical outcome measures). Patients were voluntarily recruited as part of the "Gainboy study" randomized controlled trial. ${ }^{30}$ For this pilot study, only preintervention measures were used. The study was approved by the medical ethical committee Arnhem-Nijmegen, the Netherlands (NL41708.091.12)/ 2012/390); all parents provided written informed consent, and adolescent boys 12 years and older provided assent. All data were handled according to the guidelines of Good Clinical Practice (GCP).

\subsection{Instruments}

\section{\begin{tabular}{l|l}
2.2 .1 & Sensors
\end{tabular}}

The participants were instructed to wear three accelerometers (MOX Accelerometry; Maastricht Instruments BV, Maastricht, the Netherlands) for at least 1 day but preferably 3 consecutive days. The
TABLE 1 Patient characteristics

\begin{tabular}{|c|c|c|}
\hline Variables & $\begin{array}{l}\text { Participants, } \\
\text { n }\end{array}$ & Mean \pm SD (range) \\
\hline Age, y & 16 & $12.4 \pm 3.2(7-17)$ \\
\hline Brooke scale score & 16 & \\
\hline 1 & 3 & \\
\hline 2 & 8 & \\
\hline 3 & 4 & \\
\hline 4 & 1 & \\
\hline Vignos scale score & 16 & \\
\hline 2 & 2 & \\
\hline 3 & 2 & \\
\hline 4 & 1 & \\
\hline 8 & 2 & \\
\hline 9 & 9 & \\
\hline Total PUL scale score & 16 & $55.7 \pm 15.8(27-74)$ \\
\hline Duration, min & 15 & $1601.0 \pm 506.2(390-2239)$ \\
\hline Intensity LA, bouts/min & 15 & $306.3 \pm 138.1(120-571)$ \\
\hline $\begin{array}{l}\text { Intensity UA, bouts/ } \\
\text { min }\end{array}$ & 15 & $231.5 \pm 95.2(92-387)$ \\
\hline $\begin{array}{l}\text { Intensity wheelchair/ } \\
\text { trunk, bouts/min }\end{array}$ & 15 & $70.3 \pm 50.7(36-191)$ \\
\hline $\begin{array}{l}\text { Orientation-low, \% of } \\
\text { time }\end{array}$ & 15 & $72.1 \pm 19.3(22-97)$ \\
\hline $\begin{array}{l}\text { Orientation-middle, \% } \\
\text { of time }\end{array}$ & 15 & $24.1 \pm 15.6(3-61)$ \\
\hline $\begin{array}{l}\text { Orientation-high, \% of } \\
\text { time }\end{array}$ & 15 & $3.8 \pm 4.8(0-17)$ \\
\hline $\begin{array}{l}\text { Frequency of UA } \\
\text { transfer low-middle, } \\
\text { per } h\end{array}$ & 15 & $28.9 \pm 15.4(4.9-52.8)$ \\
\hline $\begin{array}{l}\text { Frequency of UA } \\
\text { transfers } \\
\text { middle-high, per h }\end{array}$ & 15 & $4.7 \pm 7.2(0.2-27.6)$ \\
\hline
\end{tabular}

Abbreviations: LA, lower arm; PUL scale, Performance of Upper Limb scale; UA, upper arm.

accelerometers measure accelerations in three directions with a sample frequency of $25 \mathrm{~Hz}$ and are capable of measuring activity during a period of at least 7 days. One accelerometer was fixed on the upper arm (UA), one on the lower arm (LA), and one on the wheelchair or the trousers to discriminate movements of the arm from movements of the rest of the body. Patients were instructed to take the accelerometers off during sleeping, showering, and swimming. To estimate the amount of daily activity, three parameters were calculated from the acceleration data of each sensor according to a set of standardized procedures. ${ }^{28}$ We chose to use intensity, level of arm elevation (orientation), and elevation rate (frequency of arm elevation) as parameters because these were expected to fit with the functional abilities of boys/adolescents with DMD. ${ }^{23,24,27-29}$

The first parameter was activity counts (intensity), which was calculated by integrating the acceleration during 1-minute episodes and 


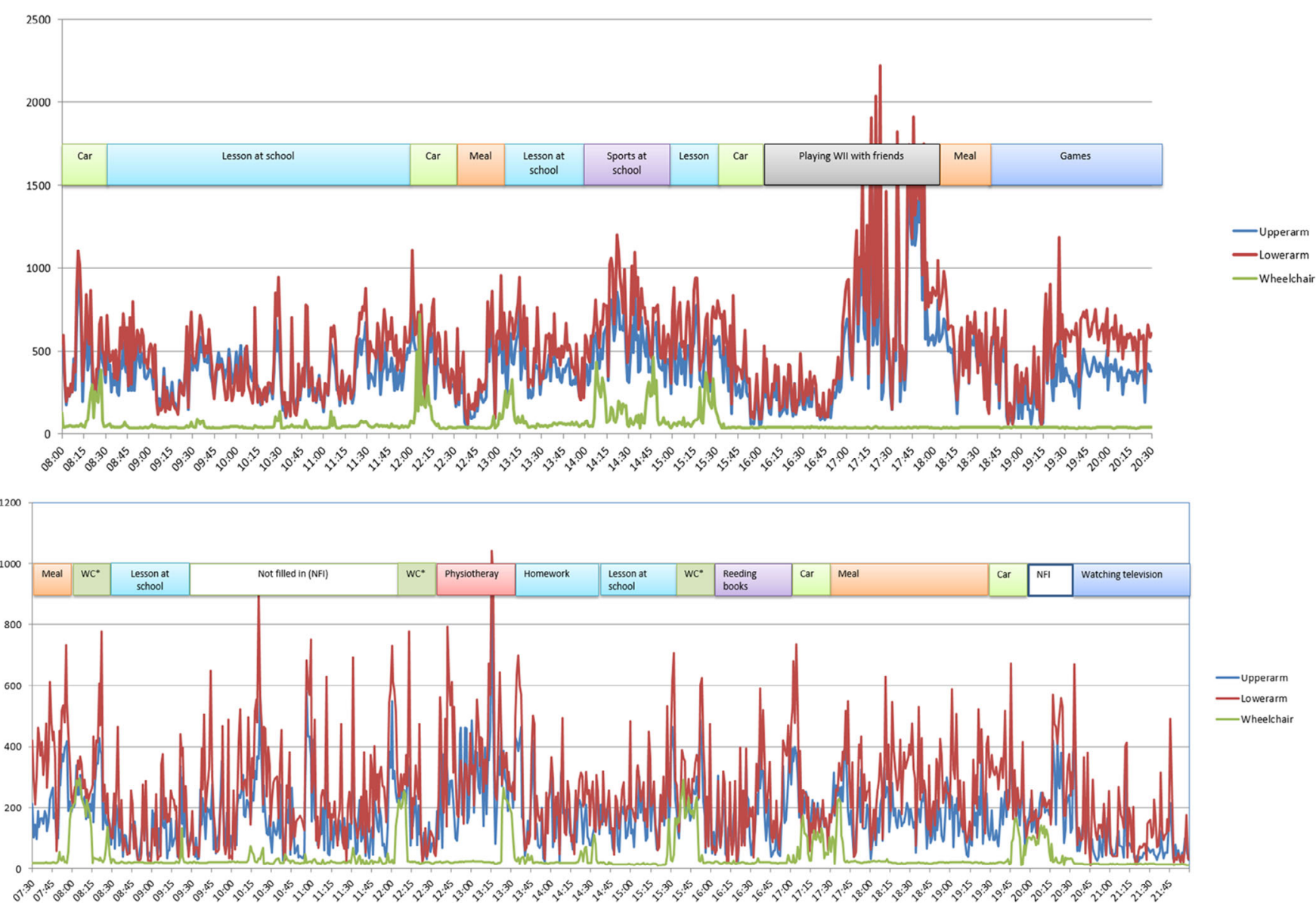

FIGURE 1 Two examples of measurements of upper arm (UA), lower arm (LA) and wheelchair activity compared with the information recorded in the diaries of two participants. Y-axis is intensity (counts/min). In the first participant (top graph), higher activity levels for LA and UA can be observed during sports and during playing with a home video game with a handheld remote controller. In addition, the sensor on the wheelchair shows activity when driving in the car or during sports. The results of the second participant show most activity of the UA and LA during therapy and less activity during watching television. Wheelchair activity can be clearly distinguished during driving in a car and when using the wheelchair, for example for going to the toilet at school, although, at about 19:45, the starting time of driving car and measured activity of the wheelchair is not exactly the same

summing this outcome over all three axes. A constant acceleration of $1 \mathrm{~g}$ (gravitational constant) during 1 minute corresponds with 1000 counts. ${ }^{28}$ The second parameter was level of elevation during a period of 1 second, also referred to as orientation. Data were categorized as low $\left(<45^{\circ}\right)$, middle $\left(45^{\circ}-90^{\circ}\right)$, or high $\left(>90^{\circ}\right)$ elevation of the arm according to the UA sensor. ${ }^{29}$ The third parameter was transfer of arm elevation, which was the frequency of elevation of the arm from low to middle elevation and from middle to high elevation.

\subsection{2 $\quad$ Clinical outcome measures}

Patients completed a physical activity diary (a diagram on paper) for 2 to 3 consecutive days. Every half hour they recorded which activity was performed. Because it was difficult to quantitate the data recorded the diary, we visually compared the information from the diary and the data from accelerometers for two random participants. In addition, we compared our results with two existing and validated scales for upper extremity functioning, the Brooke scale and the Performance of Upper Limb (PUL) scale because there is no definite gold standard for measuring activity in daily life. The Brooke scale was used to classify UE functioning with scores from 1 to 6 (higher scores indicate worse functionality). ${ }^{31}$ The PUL scale is a validated functional test that assesses UE function at the shoulder, mid-elbow, and hand. ${ }^{32}$ The total sum score ranges from 0 to 74 , with higher scores indicating better function. We also compared our results with a validated scale for ambulation, the Vignos scale (range 1-10; higher scores indicate worse functionality). The Brooke, Vignos, and PUL scales were all performed on the same day, prior to wearing the sensors.

\section{3 | Statistical analyses}

Data were analyzed in MATLAB 7.12 (The MathWorks, Natick, Massachusetts). Statistical analyses were performed in SPSS 24 for Windows (IBM, Armonk, New York). Spearman correlation coefficient 
(A)

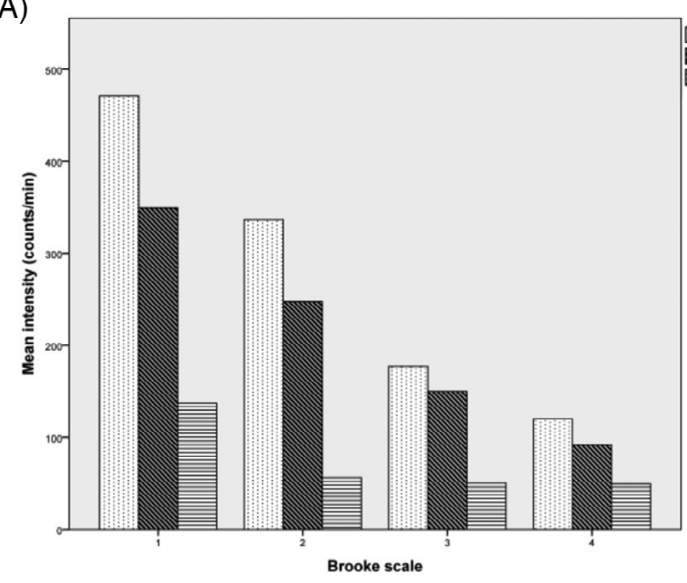

(B)

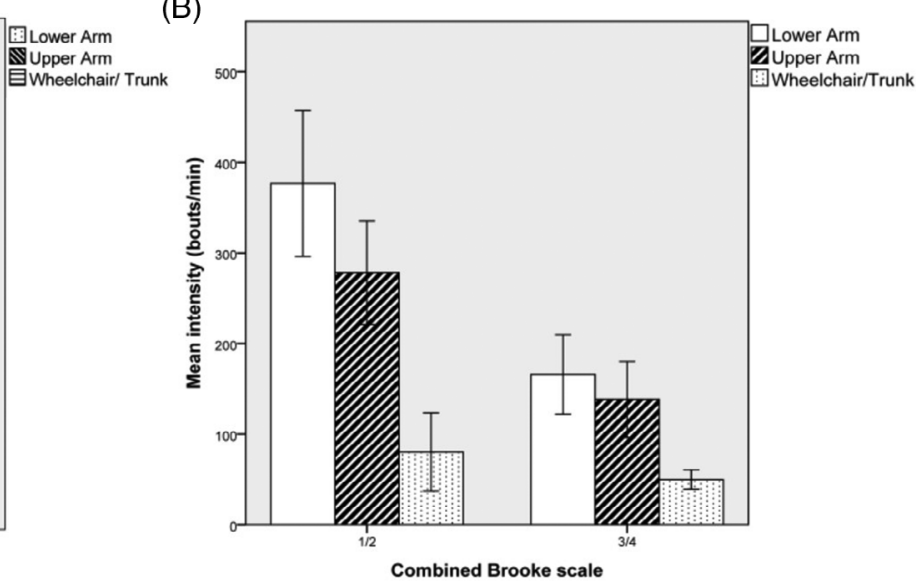

(C)

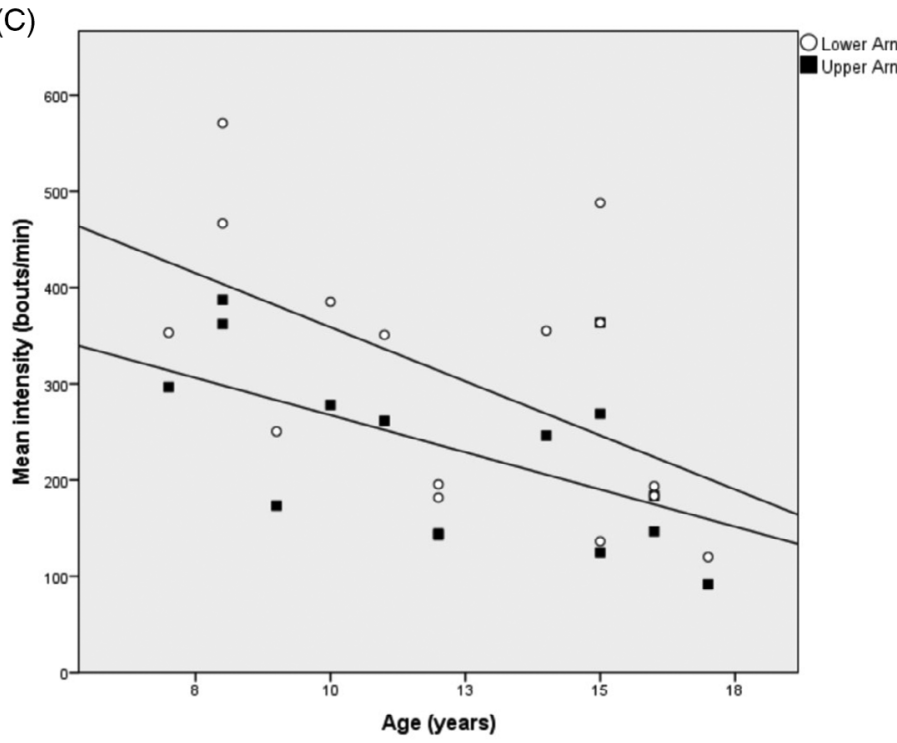

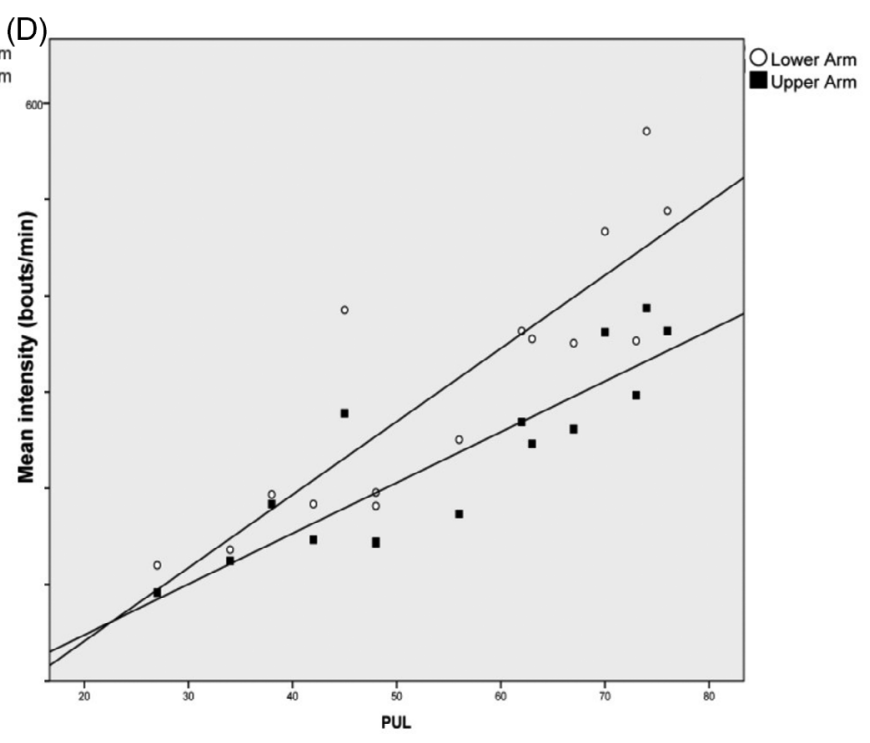

FIG URE 2 A, Mean intensity (activity count/min) in different Brooke scale scores. B, Mean intensity (activity count/min) in the combined Brooke scale scores (Brooke scale scores 1 and 2; Brooke scale scores 3 and 4). Error bars (b) indicate 95\% confidential interval. C, Mean intensity (activity count/ $\mathrm{min}$ ) in relation to the age of the patients. D, Mean intensity (activity count/minute) in relation to the Performance of Upper Limb (PUL) scale score

was used to assess the correlation between intensity, orientation, and frequency of transfers and the PUL scale result and with age. Correlation coefficients were interpreted as 0 to 0.25 , little to none; 0.26 to 0.49 , low; 0.50 to 0.69 , moderate; 0.70 to 0.89 , high; and $\geq 0.90$, very high. ${ }^{33}$ Mean differences in accelerometer parameters (intensity, orientation, and frequency of transfers of arm elevation) between participants with a Brooke score of 1 or 2 and those with a Brooke score of 3 or 4 were calculated by using independent $t$ tests. In all tests, $P<.05$ was considered statistically significant.

\section{3 | RESULTS}

Sixteen boys/adolescent boys with DMD were included, with a mean age of $12.4 \pm 3.2$ years (range, 7-17). Eleven participants had a Brooke score of 1 or 2, and five had a Brooke score of 3 or 4 (Table 1). Participants wore the accelerometers for a mean of 29 hours spread over a maximum period of 3 days (range, 6.5-37 hours). In one participant (age 13 years, Brooke score 2, total PUL scale score 73), the accelerometers did not work. In two other participants, the accelerometer stopped measuring after 1 day; in these two patients, we used the data from day 1 only.

There seemed to be a clear relationship between the activities recorded in the diary by the participants and the activity measured by the accelerometers (Figure 1). It becomes clear (Figure 1) that, in both patients, the total level of wheelchair activity is relatively small compared with the activity levels of the LA vs UA except for driving in a car (participant 2). Even during sports (participant 2), arm activity levels can be clearly distinguished from the higher than normal wheelchair activity level.

\subsection{Intensity}

Figure $2 \mathrm{~A}$ shows that the intensity (activity count/min) of the UE is lower in patients with higher Brooke scales. Because of the 
(A)

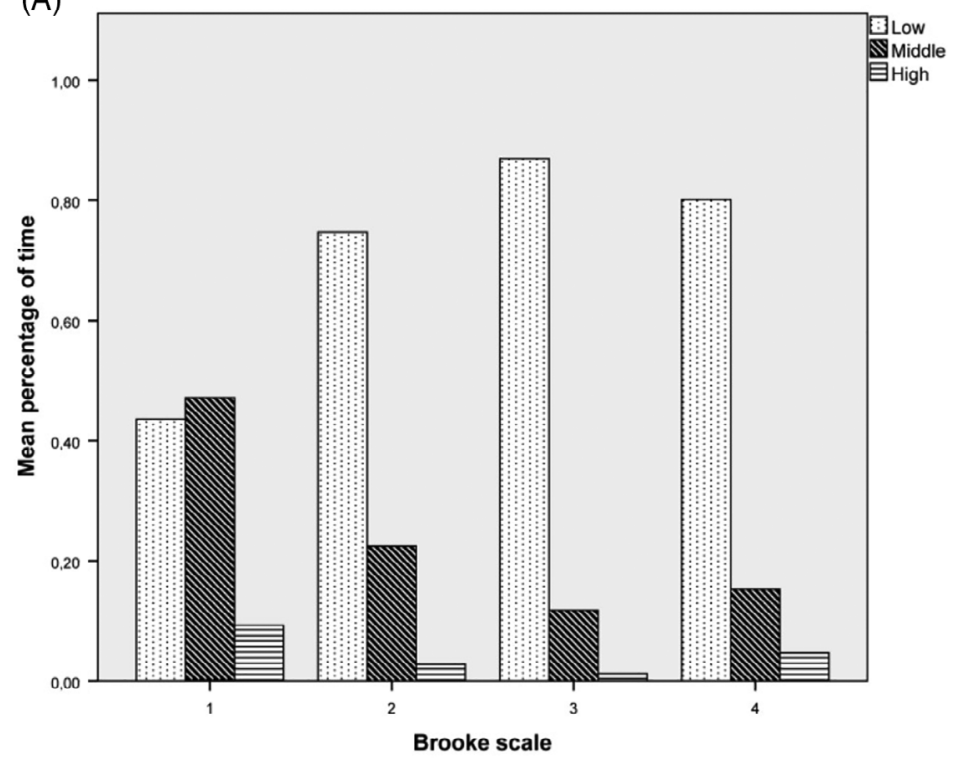

(B)

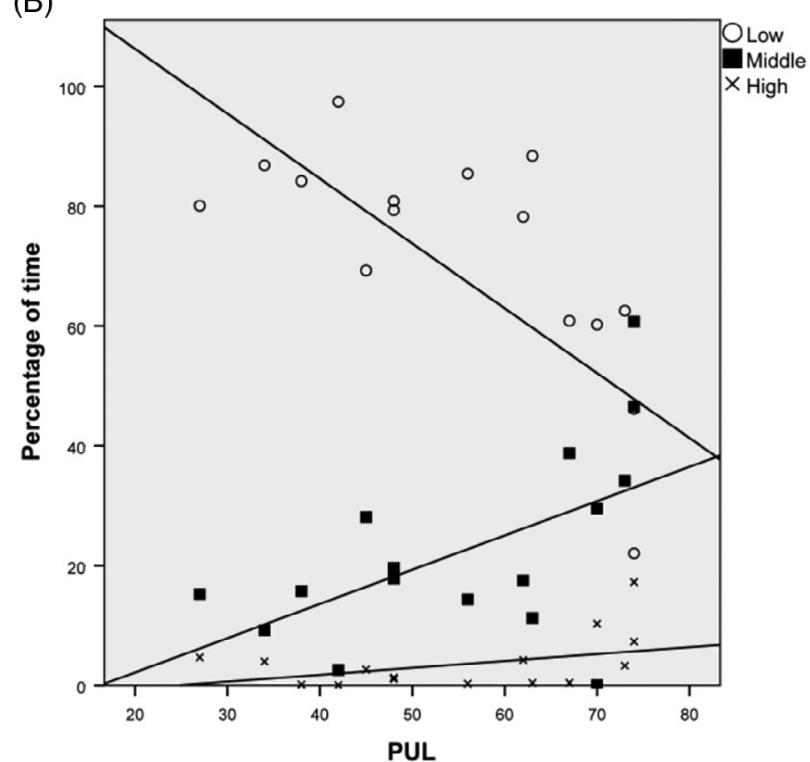

FIGURE 3 A, Percentage of time in a specific orientation with the upper arm (low, $<45^{\circ}$; middle, $45^{\circ}-90^{\circ}$; and high $>90^{\circ}$ ) for different Brooke scale scores. B, Percentage of time in a specific orientation with the upper arm (low, $<45^{\circ}$; middle, $45^{\circ}-90^{\circ}$; and high $>90^{\circ}$ ) in relation to the Performance of Upper Limb (PUL) scale score
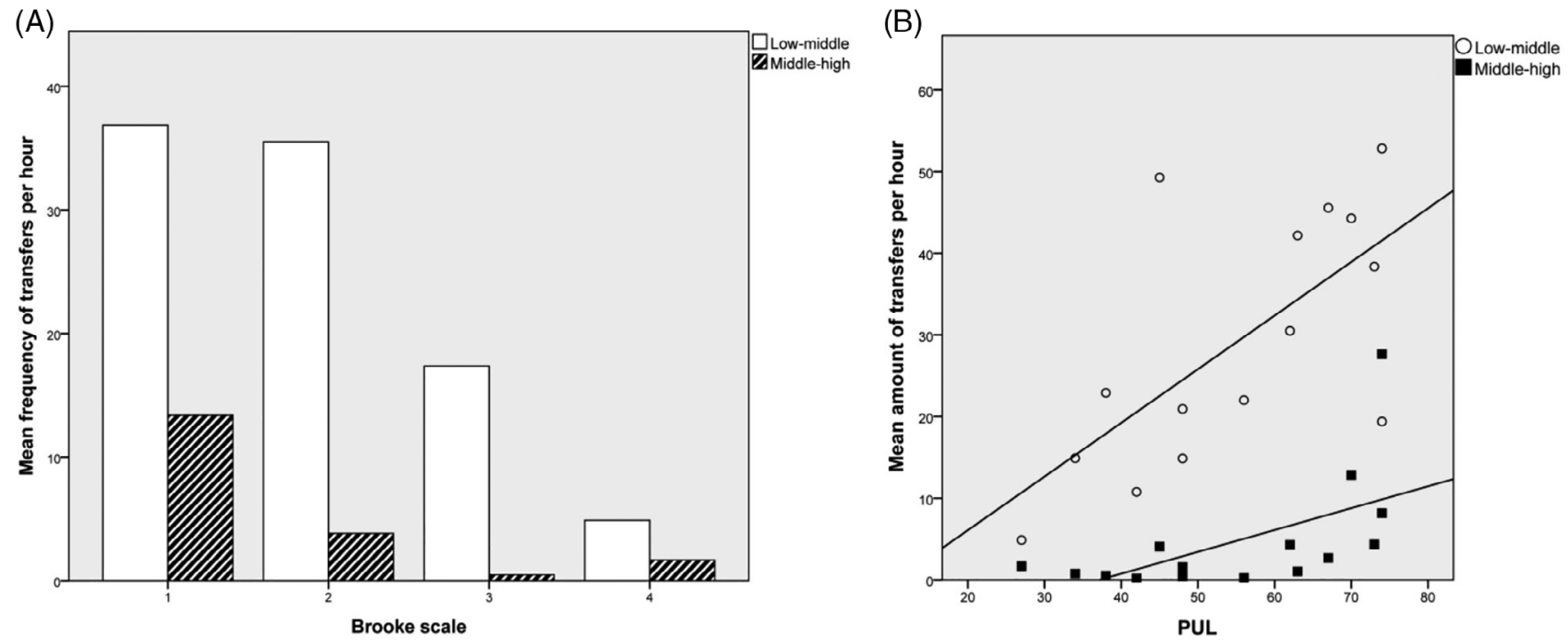

FIGURE 4 A, Mean amount of transfers of arm elevation per hour in patients with different Brooke scale scores. B, Transfers of upper arm elevation per hour in relation to the Performance of Upper Limb (PUL) scale score

small number of patients per Brooke scale score, participants were grouped into two groups according to their Brooke scale score (Figure 2B). The mean intensity of both LA and UA is about twofold higher in patients with a Brooke scale score of 1 or 2 (LA mean 378 counts/min, SD 119; UA mean 279 counts/min, SD 84) compared with a Brooke scale score of 3 or 4 (LA mean 166 counts/min, SD 35; UA mean 138 counts/min, SD 33; $P<.05)$. The intensity of UA and LA activity correlated moderately with age, UA $(R=-0.54)$, and LA $(R=-0.55$; both $P<.05$; Figure $2 C$ ). A very high correlation was seen between the intensity of UA and LA ( $R=0.95, P<.01)$. There was a high correlation between intensity and PUL scale score (LA: $R=0.82$, $P<.01$; UA: $R=0.84, P<.01$; Figure 2D).

Because of the small number of patients per Vignos scale score, participants were grouped into two groups according to their Vignos scale score. The mean intensity of both LA and UA is about 1.5-fold higher in patients with a Vignos scale score of 2 to 4 (LA mean 405 counts/min, SD 125; UA mean 297 counts/min SD 84) compared with a Vignos scale score of 8 or 9 (LA mean 257 counts/min, SD 120; UA mean 198 counts/min, SD 85; $P=.05$ ). 


\subsection{Orientation of UA}

For the whole group, the mean time spent in low orientation was the highest (67.6\%); less time (22.6\%) was spent in middle orientation, and the least time was spent in high orientation. For participants with a Brooke scale score of 1 , the mean percentage of time spent in low orientation was $43.6 \%$, mean percentage of time spent in middle orientation $47.2 \%$, and mean percentage of time spent in high orientation $9.3 \%$ (Figure $3 \mathrm{~A}$ ).

For the combined Brooke scale groups, mean percentage of time in low orientation was $65.4 \%$ in those with a Brooke scale score of 1 or 2 and $85.5 \%$ in those with a Brooke scale score of 3 or $4(P=.05)$. The mean percentage of time in middle orientation was $29.9 \%$ in the group with a Brooke scale score of 1 or 2 and $12.5 \%$ in the group with Brooke scale score of 3 or $4(P<.05)$. The mean percentage of time in high orientation was $4.7 \%$ in the group with a Brooke scale score of 1 or 2 and $2.0 \%$ in the group with a Brooke score of 3 or $4(P=.3)$.

\section{3 | Transfers of arm elevation}

No relevant difference was seen in the mean amount of transfers of UA elevation per hour between low to middle (mean 28.9) and middle to low (mean 28.92) or between middle to high (4.69) and high to middle (mean 4.82) orientation. Therefore, only the transfers from low to middle and middle to high orientation are shown (Figure 4A). The mean amount of transfers from low to middle orientation in participants with a Brooke scale score of 1 or 2 was 35.9 per hour (SD 13.4); in participants with a Brooke scale score 3 or 4 , it was 14.9 per hour (SD 7.4; $P<.01$ ). The mean amount of transfers from middle to high orientation in participants with a Brooke scale score of 1 or 2 was 6.7/hour (SD 8.2); in those with a Brooke scale score of 3 or 4 , it was $0.7 /$ hour (SD 0.6; $P=.14$ ). There was a moderate correlation between number of transfers per hour and PUL scale score from low-middle $(R=0.59, P<.05)$ and from middle-high $(R=0.69, P<.01)$, and there was a high correlation between the total number of transfers per hour and the PUL scale score $(R=0.76, P<.01$; Figure $4 \mathrm{~B})$.

\section{DISCUSSION}

Le Moing et $\mathrm{al}^{27}$ showed that variables of a wireless movement monitor correlated well with the scores obtained by using other previously validated tests in the UE, but this was in a controlled setting and not in the at-home situation. We showed that in boys/adolescents with DMD, the results of the at-home-measured parameters are related to our current standards for measuring function of the upper extremity (Brooke and PUL scale scores). ${ }^{31,32}$ Although these two latter functional outcomes provide information about the level of functional capacity and activity, it is unclear how these can be generalized to actual daily life performance. Evaluating UE function in the home setting with sensors will give better insights into daily functioning at home. Our finding that accelerometry can be used as an objective outcome measurement correlates with findings in studies of patients with different diagnoses and with findings from studies for lower extremity function in DMD. ${ }^{12,16,23,26}$

There appears to be a clear relationship between the activities recorded in the diaries by the participants and the activity measured by the accelerometers. The comparison between the two (Figure 1) shows that the use of an accelerometer is sensitive to differences between activities; however, demonstrating this was not the objective of our study. In the second participant in Figure 1 (bottom graph), some information from the diary was missing, and a difference was seen in the starting time of driving according to the diary and the measurements of the accelerometers. It is reasonable to assume that starting times in the diary are not very precise.

Only a small portion of the total intensity of movements was attributable to movements of the wheelchair or trunk, probably because most of the time the children sat (even those without a wheelchair) or stayed in one place with their wheelchair. The simultaneous use of two different sensors (UA and LA) appears to convey no meaningful advantage compared with a single sensor for the measurement of intensity because there was a very high correlation between the two. Therefore, future studies could consider the use of only one sensor instead of two on the UE (placed close to the wrist) and one sensor on the wheelchair, especially because some participants described wearing the sensors as bothersome. The accelerometers were chosen for their light weight, small size, and ability to collect data for long periods as well as the accessibility of raw data. New portable electronic devices with many types of sensors, such as smartwatches, may be used in future studies. Although the percentage of time spent in high orientation was lowest in participants with Brooke scale scores of 3 and 4 , some movements were classified in this category. This was unexpected because these participants were unable to move the arms independently above shoulder level. They could have used compensatory lateral flexion of the trunk, thus lifting their arms, or, alternatively, their arm movements may have been supported by caregivers or mechanical arm supports. This cannot be determined with the methods used in this study.

Limitations of this study include the relatively small sample, especially the low number of participants with Brooke scale scores of 3 or 4. This also could explain why some scores in the Brooke 4 group were higher than those in the Brooke 3 group. However, the prevalence of this disease in the community is very low, and this is an exploratory pilot study. We believe that the results are sufficiently encouraging to consider this approach in a broader population. Another limitation is that we measured a relatively short time period because of a concern of the burden to the boys/adolescents of filling out diaries and wearing sensors for longer periods. We also did not correct for the period during which the sensors were worn (season, weekdays, or weekend), although a recent study showed an effect of season on the activity pattern of children with neuromuscular diseases. ${ }^{34} \mathrm{~A}$ third limitation is that we did not select participants with specific mutations because as our research questions where more general, assessing the feasibility and validity of the method. A final 
limitation is that no data were available for one patient, and that data for two other patients were available for only 1 day because the accelerometers stopped functioning. Future studies should consider using sensors with in-the-moment real time data, such as an application with an option to correct technical problems with the sensors.

In conclusion, our study provides new insights into the measurement of daily activity in boys/adolescents with DMD in at-home situations. In boys/adolescents with DMD, both the intensity of activity and the frequency of transfers of the upper extremity are related to our current standards for measuring functioning of the arms (Brooke and PUL scales). The intensity of activity of the upper extremity as measured with accelerometers in daily life is related to the current standard for measuring activity in the at-home situation by the use of diaries. Accelerometry seems to be a valid method to measure activity at home.

\section{ACKNOWLEDGMENTS}

The authors thank the boys and their parents for participating in this study and the Duchenne Parent Project for funding this study.

\section{ETHICAL PUBLICATION STATEMENT}

We confirm that we have read the Journal's position on issues involved in ethical publication and affirm that this report is consistent with those guidelines.

\section{ORCID}

Merel Jansen (D) https://orcid.org/0000-0003-3756-8241

\section{REFERENCES}

1. Bello L, Gordish-Dressman H, Morgenroth LP, et al. Prednisone/ prednisolone and deflazacort regimens in the CINRG Duchenne Natural History Study. Neurology. 2015;85:1048-1055.

2. Eagle M, Baudouin SV, Chandler C, Giddings DR, Bullock R, Bushby K. Survival in Duchenne muscular dystrophy: improvements in life expectancy since 1967 and the impact of home nocturnal ventilation. Neuromuscul Disord. 2002;12:926-929.

3. Kohler M, Clarenbach CF, Bahler C, Brack T, Russi EW, Bloch KE. Disability and survival in Duchenne muscular dystrophy. J Neurol Neurosurg Psychiatry. 2009;80:320-325.

4. Janssen MM, Bergsma A, Geurts AC, de Groot IJ. Patterns of decline in upper limb function of boys and men with DMD: an international survey. J Neurol. 2014;261:1269-1288.

5. Matthews E, Brassington R, Kuntzer T, Jichi F, Manzur AY. Corticosteroids for the treatment of Duchenne muscular dystrophy. Cochrane Database Syst Rev. 2016;5(5):CD003725.

6. Jansen M, van Alfen N, Geurts AC, de Groot IJ. Assisted bicycle training delays functional deterioration in boys with Duchenne muscular dystrophy: the randomized controlled trial "no use is disuse". Neurorehabil Neural Repair. 2013;27:816-827.

7. Henricson EK, Abresch RT, Cnaan A, et al. The cooperative international neuromuscular research group Duchenne natural history study: glucocorticoid treatment preserves clinically meaningful functional milestones and reduces rate of disease progression as measured by manual muscle testing and other commonly used clinical trial outcome measures. Muscle Nerve. 2013;48:55-67.

8. McDonald CM, Henricson EK, Abresch RT, et al. Long-term effects of glucocorticoids on function, quality of life, and survival in patients with Duchenne muscular dystrophy: a prospective cohort study. Lancet. 2017;391:451-461.

9. McDonald CM, Henricson EK, Han JJ, et al. The 6-minute walk test as a new outcome measure in Duchenne muscular dystrophy. Muscle Nerve. 2010;41:500-510.

10. Mercuri E, McDonald C, Mayhew A, et al. International workshop on assessment of upper limb function in Duchenne muscular dystrophy: Rome, 15-16 February 2012. Neuromuscul Disord. 2012;22:10251028.

11. Bray P, Bundy AC, Ryan MM, North KN. Can in-the-moment diary methods measure health-related quality of life in Duchenne muscular dystrophy? Qual Life Res. 2017;26:1145-1152.

12. Koene S, Dirks I, van Mierlo E, et al. Domains of daily physical activity in children with mitochondrial disease: a 3D accelerometry approach. JIMD Rep. 2017;36:7-17.

13. McDonald CM, Widman LM, Walsh DD, Walsh SA, Abresch RT. Use of step activity monitoring for continuous physical activity assessment in boys with Duchenne muscular dystrophy. Arch Phys Med Rehabil. 2005;86:802-808.

14. Ganea R, Jeannet P, Paraschiv-lonescu A, et al. Gait assessment in children with Duchenne muscular dystrophy during long-distance walking. J Child Neurol. 2012;27:30-38.

15. Jeannet PY, Aminian K, Bloetzer C, Najafi B, Paraschiv-lonescu A Continuous monitoring and quantification of multiple parameters of daily physical activity in ambulatory Duchenne muscular dystrophy patients. Eur J Paediatr Neurol. 2011;15:40-47.

16. Davidson ZE, Ryan MM, Kornberg AJ, Walker KZ, Truby H. Strong correlation between the 6-minute walk test and accelerometry functional outcomes in boys with Duchenne muscular dystrophy. J Child Neurol. 2015;30:357-363.

17. Fowler EG, Staudt LA, Heberer KR, et al. Longitudinal community walking activity in Duchenne muscular dystrophy. Muscle Nerve. 2017;57:401-406.

18. McDonald RL, Wilson GN, Molloy A, Franck LS. Feasibility of three electronic instruments in studying the benefits of adaptive seating. Disabil Rehabil Assist Technol. 2011;6:483-490.

19. Rowlands AV. Accelerometer assessment of physical activity in children: an update. Pediatr Exerc Sci. 2007;19:252-266.

20. Gorter JW, Noorduyn SG, Obeid J, Timmons BW. Accelerometry: a feasible method to quantify physical activity in ambulatory and nonambulatory adolescents with cerebral palsy. Int J Pediatr. 2012; 2012:329284.

21. Clanchy KM, Tweedy SM, Boyd RN, Trost SG. Validity of accelerometry in ambulatory children and adolescents with cerebral palsy. Eur J Appl Physiol. 2011;111:2951-2959.

22. Gebruers N, Vanroy C, Truijen S, Engelborghs S, De Deyn PP. Monitoring of physical activity after stroke: a systematic review of accelerometrybased measures. Arch Phys Med Rehabil. 2010;91:288-297.

23. Narai E, Hagino H, Komatsu T, Togo F. Accelerometer-based monitoring of upper limb movement in older adults with acute and subacute stroke. J Geriatr Phys Ther. 2016;39:171-177.

24. Noorkõiv $\mathrm{M}$, Rodgers $\mathrm{H}$, Price $\mathrm{Cl}$. Accelerometer measurement of upper extremity movement after stroke: a systematic review of clinical studies. J Neuroeng Rehabil. 2014;11:144.

25. Carpinella I, Cattaneo D, Ferrarin M. Quantitative assessment of upper limb motor function in multiple sclerosis using an instrumented action research arm test. J Neuroeng Rehabil. 2014;11:67.

26. Uswatte G, Foo WL, Olmstead H, Lopez K, Holand A, Simms LB. Ambulatory monitoring of arm movement using accelerometry: an objective measure of upper-extremity rehabilitation in persons with chronic stroke. Arch Phys Med Rehabil. 2005;86:1498-1501.

27. Le Moing A, Seferian AM, Moraux A, et al. A movement monitor based on magneto-inertial sensors for non-ambulant patients with Duchenne muscular dystrophy: a pilot study in controlled environment. PLoS One. 2016;11:e0156696. 
28. Meijer K, Annegarn J, Lima Passos V, et al. Characteristics of daily arm activities in patients with COPD. Eur Respir J. 2014;43:1631-1641.

29. Annegarn J, Spruit MA, Schols AM, et al. Assessment of intensity and elevation of arm movements during activities of daily life. In: Annegarn J, ed. Daily Activity Monitoring in Patients with COPD. Maastricht, The Netherlands: University of Maastricht; 2012:77-89.

30. Heutinck L, Jansen M, van den Elzen Y, van der Pijl D, de Groot IJ. Virtual reality computer gaming with dynamic arm support in boys with Duchenne muscular dystrophy. J Neuromuscul Dis. 2018;5(3): 359-372.

31. Lue Y, Su C, Yang R, et al. Development and validation of a muscular dystrophy-specific functional rating scale. Clin Rehabil. 2006;20: 804-817.

32. Pane M, Mazzone ES, Fanelli L, et al. Reliability of the Performance of Upper Limb assessment in Duchenne muscular dystrophy. Neuromuscul Disord. 2014;24:201-206.
33. Munro BH. Correlation. In: Munro BH, ed. Statistical Methods for Health Care Research. Vol 1. Philadelphia, PA: Lippincott, Williams \& Wilkins; 2005:239-258.

34. de Vries PR, Janssen M, Spaans E, et al. Natural variability of daily physical activity measured by accelerometry in children with a mitochondrial disease. Mitochondrion. 2019;47:30-37.

How to cite this article: van der Geest A, Essers JMN,

Bergsma A, Jansen M, de Groot IJM. Monitoring daily physical activity of upper extremity in young and adolescent boys with Duchenne muscular dystrophy: A pilot study. Muscle Nerve.

2020;61:293-300. https://doi.org/10.1002/mus.26763 